\title{
SIMULASI DAN ANALISIS ANTENA UWB TRISULA 2,4 GHz MENGGUNAKAN ANSOFT HFSS 13
}

\author{
Elta Sonalitha $^{1)}$, Andry Fakhrurizal ${ }^{2)}$, Chotib Alwan ${ }^{3)}$, Busro Akramul ${ }^{4)}$, Subhan Zamroni ${ }^{5)}$. \\ ${ }^{1}$ Fakultas Teknologi Informasi, Universitas Merdeka Malang \\ email: elta.sonalitha@unmer.ac.id \\ ${ }^{2}$ Fakultas Teknologi Informasi, Universitas Merdeka Malang \\ email: andry.fakhrurizal@outlook.com \\ ${ }^{3}$ Fakultas Teknik Elektro, Universitas Brawijaya Malang \\ email: omahkusiip@yahoo.com \\ ${ }^{4}$ Fakultas Teknik, Prodi Teknik Informatika, Universitas Islam Madura \\ email: busro.umam@gmail.com \\ ${ }^{5}$ Fakultas Teknik dan Ilmu Komputer, Universitas Raden Rahmat Malang \\ email: admin@uniradenrahat.ac.id
}

\begin{abstract}
Simulating trident-shaped UWB antenna using Ansoft software 13. HFSS simulation was conducted to determine the parameters - the antenna parameters, namely : VSWR, return loss and axial ratio. After the simulation is done and the results of the measurements parameters - the parameters of the antenna, it will be described as well like creating / fabricating antenna using a simple manner. Antennas are already in - fabrication will certainly be able to was measured using a measuring instrument that is in fact, not a simulation.
\end{abstract}

\section{Keywords : Trisula Antenna, Ansoft HFSS 13, VSWR, return loss, Axial ratio}

\section{PENDAHULUAN}

Perkembangan teknologi dewasa ini telah membawa perubahan pada manusia dalam berbagai aspek kehidupan, mulai dari konsumsi sehari-hari, sampai pada pemanfaatan teknologi untuk commercial. Namun hal penting yang menjadi pandangan utama dalam pemanfaatan teknologi ini adalah bahwa kemudahan akan didapatkan dalam aktivitas hidup manusia. Sebagai contoh, perkembangan teknologi telekomunikasi membuat manusia tidak perlu berpergian jauh untuk menyampaikan pesan, perkembangan teknologi dalam bidang wireless memungkinkan penghantaran signal dalam jarak jauh, perkembangan teknologi elektronika memungkinkan dibuatnya ATM yang merupakan fasilitas untuk mengambil uang tanpa harus khawatir hilang ketika uang itu selalu dibawa. Satelit, antena, dan lain sebagainya.

Bermacam perbedaan frekuensi yang dipergunakan ini dapat di atasi dengan perancangan antena yang memiliki banyak frekuensi, atau biasa disebut multiband/wideband antenna yang di kenal dengan antena UWB (Ultra Wideband Antenna). Dan salah satu jenis antena yang mudah dibuat, dan memiliki cost yang relatif kecil untuk perancangannya adalah dengan menggunakan antena mikrostrip.

Untuk membuat suatu antena mikrostrip dapat bekerja pada bermacam-macam aplikasi adalah dengan membuatnya menghasilkan lebih dari satu frekuensi resonansi, atau yang biasa disebut antena multiband.

Ada 3 teknik yang umumnya digunakan untuk mendapatkan antena multiband, yakni dengan teknik Orthogonal mode Dual frequency Patch Antenna, Multi patch Dual Frequency Antenna, dan Reactively loaded Patch Antenna. Salah satu cara dalam teknik Reactively loaded Patch Antenna adalah dengan penggunaan slot untuk menghasilkan antena multiband.

Dalam pembuatan makalah ini kami akan merancang sebuah antena mikrostip multiband/Ultra Wideband yang dapat menerima salah satunya adalah frekuensi WIFI yaitu 2.4 Ghz dengan menggunakan Ansoft 13.0. Dan dianalisa VSWR atau Return Lossnya harus memenuhi kriteria yaitu VSWRnya lebih dari 1 dan kurang dari 2 dan Return Lossnua Kurang dari $-10 \mathrm{~dB}$. 


\section{Konsep Dasar Antena}

Salah satu bagian penting dari suatu stasiun radio adalah antena. Antena adalah transformator atau struktur transisi antara antena gelombang terbimbing (saluran transmisi) dengan gelombang ruang bebas atau sebaliknya, ia adalah sebatang logam yang berfungsi menerima getaran listrik dari transmitter dan memancarkannya sebagai gelombang radio. Ia berfungsi pula sebaliknya ialah menampung gelombang radio dan meneruskan gelombang listrik ke receiver.

Secara umum, antena dibedakan menjadi antena isotropis, antena omnidirectional, antena directional, antena phase array, antena optimal dan antena adaptif. Antena isotropis (isotropic) merupakan sumber titik yang memancarkan daya ke segala arah dengan intensitas yang sama, seperti permukaan bola. Antena ini tidak ada dalam kenyataan dan hanya digunakan sebagai dasar untuk merancang dan menganalisa struktur antena yang lebih kompleks. Antena omnidirectional adalah antena yang memancarkan daya ke segala arah, dan bentuk pola radiasinya digambarkan seperti bentuk donat (doughnut) dengan pusat berimpit. Antena ini ada dalam kenyataan, dan dalam pengukuran sering digunakan sebagai pembanding terhadap antena yang lebih kompleks. Contoh antena ini adalah antena dipole setengah panjang gelombang.

Antena directional merupakan antena yang memancarkan daya ke arah tertentu. Gain antena ini relatif lebih besar dari antena omnidirectional. Contoh, suatu antena dengan gain $10 \mathrm{dBi}$ (kadang-kadang dinyatakan dengan "dBic" atau disingkat "dB" saja). Artinya antena ini pada arah tertentu memancarkan daya $10 \mathrm{~dB}$ lebih besar dibanding dengan antena isotropis. Ketiga jenis antena di atas merupakan antena tunggal, dan bentuk pola radiasinya tidak dapat berubah tanpa merubah fisik antena atau memutar secara mekanik dari fisik antena. informasi ini diharapkan akan tercipta sebuah efisiensi dan efektifias kerja.

\section{Scattering Parameter Antena}

Kinerja suatu antena dapat dilihat dari parameter antena. Parameter-parameter antena yang biasanya digunakan untuk menganalisis suatu antena adalah Voltage Wave Standing Ratio (VSWR), return loss dan axial ratio.

\section{Voltage Standing Wave Ratio (VSWR)}

VSWR adalah perbandingan antara amplitudo standing wave maksimum (|V|max) dengan minimum (|V|min). Pada saluran transmisi ada dua komponen gelombang tegangan, yaitu tegangan yang dikirimkan ( $\mathrm{V} 0+$ ) dan tegangan yang direfleksikan (V0-). Perbandingan antara tegangan yang direfleksikan dengan yang dikirimkan disebut sebagai koefisien refleksi tegangan (T), yaitu :

$$
\Gamma=\frac{V_{0}^{-}}{V_{0}^{+}}+\frac{Z_{L}-Z_{0}}{Z_{L}+Z_{0}}
$$

di mana ZL adalah impedansi beban (load) dan Z0 adalah impedansi saluran lossless. Koefisien refleksi tegangan (T) memiliki nilai kompleks, yang merepresentasikan besarnya magnitudo dan fasa dari refleksi. Untuk beberapa kasus yang sederhana, ketika nilai imajiner adalah nol, maka:

a. $\mathrm{T}=-1$ : refleksi negatif maksimum, ketika saluran terhubung singkat

b. T=0: tidak ada refleksi, ketika saluran dalam keadaan matched sempurna.

c. $T=+1$ : refleksi positif maksimum, ketika saluran dalam rangkaian terbuka.

Rumus untuk mencari nilai VSWR adalah :

$$
S=\frac{|\tilde{V}|_{\max }}{|\tilde{V}|_{\min }}=\frac{1+|\Gamma|}{1-|\Gamma|}
$$

Kondisi yang paling baik adalah ketika VSWR bernilai $1(S=1)$ yang berarti tidak ada refleksi ketika saluran dalam keadaan matching sempurna. Namun kondisi ini pada praktiknya sulit untuk didapatkan. Oleh karena itu, nilai standar VSWR yang diijinkan untuk fabrikasi antena adalah $\mathrm{VSWR} \leq 2$.

\section{Return Loss}

Return loss adalah perbandingan antara amplitudo dari gelombang yang direfleksikan terhadap amplitudo gelombang yang dikirimkan. 
Return loss dapat terjadi karena adanya diskontinuitas di antara saluran transmisi dengan impedansi masukan beban (antena). Pada rangkaian gelombang mikro yang memiliki diskontinuitas (mismatched), besarnya return loss bervariasi tergantung pada frekuensi seperti yang ditunjukkan oleh :

$$
\text { return loss }=20 \log _{10}|\Gamma|
$$

Nilai dari return loss yang baik adalah di bawah 9,54 dB, nilai ini diperoleh dari nilai VSWR yaitu antara $1 \leq \mathrm{VSWR} \leq 2$. Nilai parameter ini menjadi salah satu acuan untuk melihat apakah antena sudah dapat bekerja pada frekuensi yang diharapkan atau tidak.

\section{Axial Ratio}

Nilai axial ratio menentukan polarisasi sebuah antena. Axial ratio merupakan perbandingan antara Emayor dan Eminor. Untuk circular polarization, perbandingan nilai antara Emayor dan Eminor tidak boleh lebih besar dari 3 dB. Sehingga batasan toleransi axial ratio dalam dB mempunyai circular polarization antara $0<\mathrm{AR}(\mathrm{dB}) \leq 3$. Untuk nilai axial ratio $\leq 3 \mathrm{~dB}$ maka antena memiliki circular polarization.

\section{Bandwidth}

Bandwidth merupakan rentang frekuensi kerja antena yang terbentuk setelah terpenuhinya karakteristik antena yang didesain. Bandwidth dinyatakan sebagai perbandingan antara frekuensi atas dan frekuensi bawah dalam level yang dapat diterima. Nilai bandwidth dapat dicari dengan persamaan :

$$
\begin{gathered}
B W=\frac{f_{h}-f_{l}}{f_{l}} X 100 \% \\
B W=\frac{f_{h}-f_{l}}{2}
\end{gathered}
$$

$\mathrm{BW}=$ Bandwidth

Fh $=$ Frekuensi tertinggi dalam Band

$\mathrm{Fl}=$ Frekuensi terendah dalam Band

$\mathrm{Fc}=$ Frekuensi tengah dalam Band

\section{Antena Mikrostrip}

Antena mikrostrip merupakan antena yang berbentuk papan (board) tipis dan mampu bekerja pada frekuensi yang sangat tinggi. Secara fisik antena ini terlihat sederhana karena hanya berupa lempengan semacam PCB yang cukup dikenal dalam dunia elektronika.

Dalam bentuknya yang paling dasar, sebuah antena mikrostrip terdiri dari sebuah bidang (patch) memancar salah satu sisi lapisan (substrate) dielektrik yang memiliki bidang dasar (ground plane) di sisi lain.

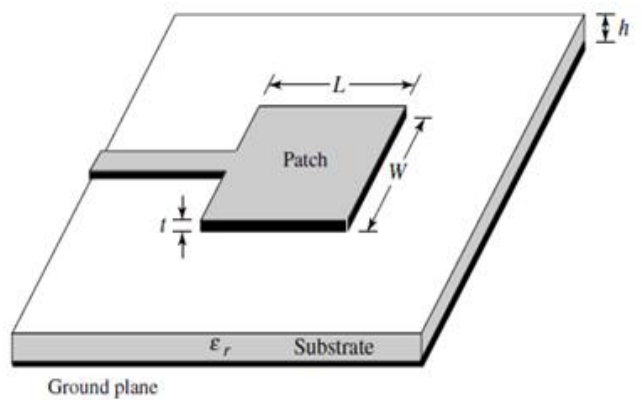

Gambar 1 Bagian-bagian Antena Mikrostrip

\section{Keuntungan dan kekurangan Antena Mikrostrip}

Bentuk yang sederhana dan ketebalan subtract yang hanya berukuran millimeter memudahkan antena ini untuk dimontasikan hamper pada seluruh tempat. Dan kekurangannya adalah gain yang di capai sangat kecilsekitar 6 $\mathrm{dBi}$, mempunyai bandwidth yang kecil dan hanya bias memancarkan sinyal dengan daya yang relative kecil maksimal 100 Watt.

\section{HASIL DAN PEMBAHASAN}

\section{Pembuatan dan Simulasi Antena Mikrostrip} Membuat Port

Langkah pertama dalam membuat antena adalah membuat port. Port terdiri dari Core, Cladding dan Jaket. Seperti pada gambar 2

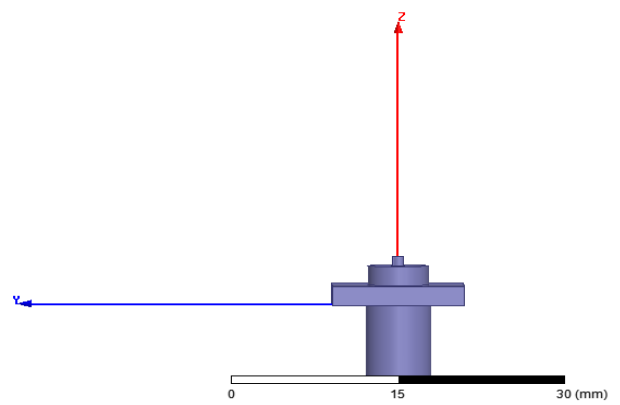

Gambar 2 Pembuatan Port 
1. Untuk Core dan Cladding buat Cylinder kemudian tetntukan posisinya dan radiusnya. Dan gunakan utilitas subtract untuk memotong/memberi lubang pada bagian tertentu dan matrial dari port gunakan gold, cladding gunakan tefflon.

2. Jaket buat dengan Box dan Cylinder lalu lalu sesuaikan posisinya dan subtract dengan yang lainagar tidak intersect kemunian gabungkan box dan cylinder tersebut, matrial untuk jaket adalah cooper.

3. Buat lumped port dengan circle, tentukan paosisinya lalu exsitationnya dengan impedansi 50 Omh buat dengan menarik garis dari tepi circle ke tengah.

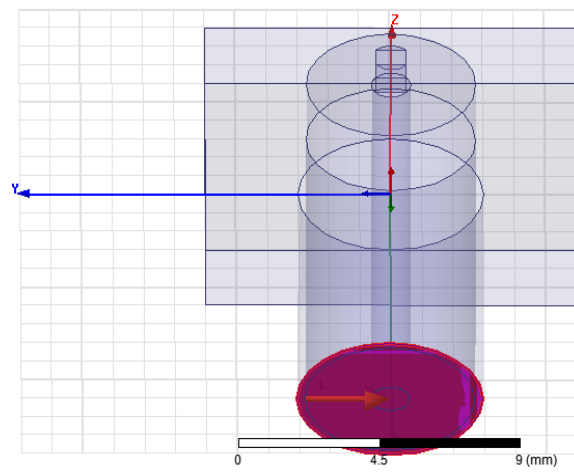

Gambar 3. Lumped Port

Membuat Substrat, Patch dan GroundPlane

1. Substrat dibuat dengan menggunakan box atur posisinya, ketebalan dan materialnya adalah FR-4 epoxy dengan permitifitas relative $\varepsilon r=4.4$.

2. Membuat Patch segitiga sama sisi sebanyak 3 buah dan feed line atau saluran transmisi dari Patch menuju ke Port dengan menggunakan rectangle kemudian atur posisinya lalu digabung (unity).

3. Membuat groundplane pada sisi lainya dengan menggunakan rectangle juga lalu diatur posisinya dan digabungkan.

4. Patch, Saluran transmisi dan Groundplane di Perfect E.

5. Buat Box dengan matrial udara tentukan posisinya dan ukuranya juga lalu di beri Radiasi Infinite Sphere.

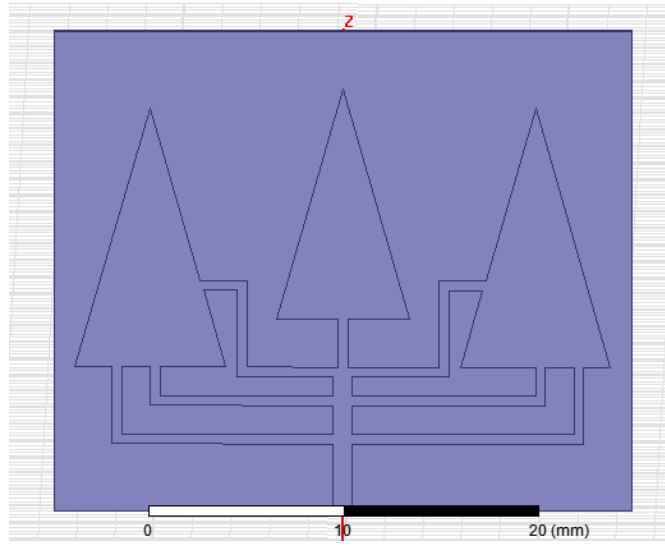

Gambar 4. Substrat dan Patch

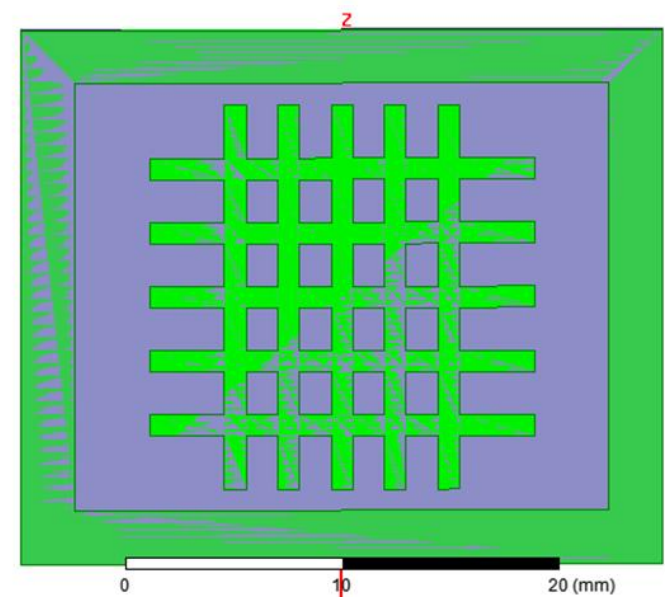

Gambar 5. Groundplane

\section{Hasil Perancangan Antena}

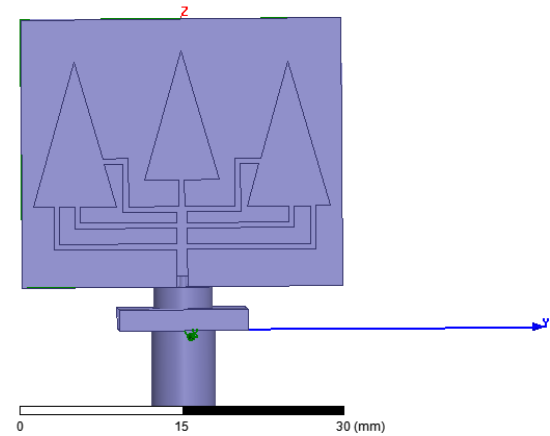

Gambar 6. Antena tampak depan 


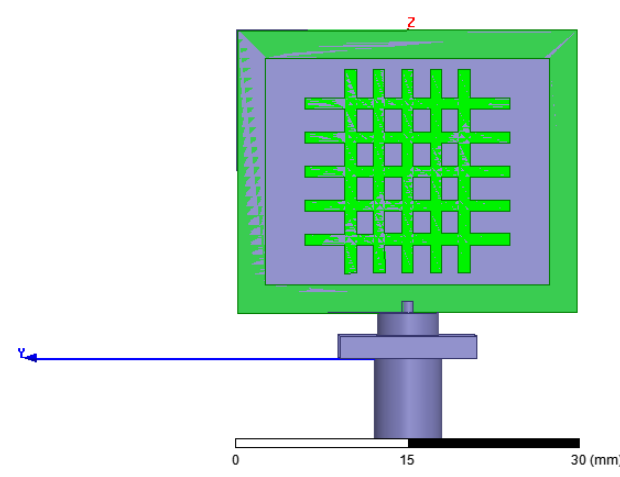

Gambar 7. Antena tampak belakang

Sebelum kita analisa model antena kita buat setup untuk analisa dengan solusi frekuensinya $2.4 \mathrm{GHz}$ dan maksimum delta s adalah 0.02 , kita buat sweep analisis dengan sweep tipe interpolasi, start $1 \mathrm{GHz}$, stop $10 \mathrm{GHz}$, step size $0.1 \mathrm{GHz}$ dan error toleransi 0.1 , kemudian di validasi kalau tidak ada error kita lanjutkan dengan analyze all.

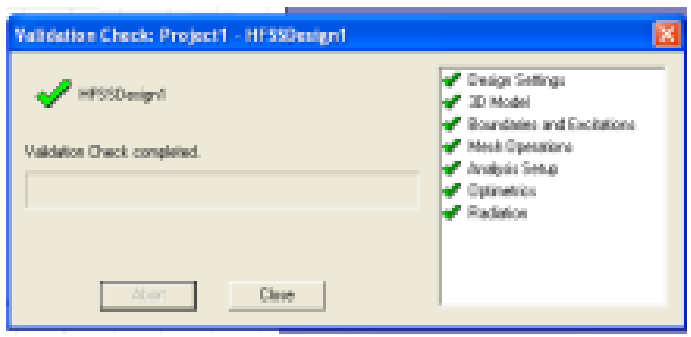

Gambar 8. Check Validasi Analyze

\section{Melihat hasil simulasi}

Untuk melihat hasil simulasi dilakukan dengan memilih HFSS Design $\rightarrow$ Result $\rightarrow$ Create Modal Solution Data Report $\rightarrow$ Rectangular Plot (VSWR dan SParameter/Return Loss). HFSS Design $\rightarrow$ Result $\rightarrow$ Create Far Fields Report $\rightarrow$ Rectangular Plot (Axial Ratio).

\section{Data analisa hasil simulasi antena}

1. Nilai Voltage Standing Wave Ratio (VSWR)

Dari uji analisa yang telah dilakukan maka di dapat nilai VSWRnya sebagai berikut.

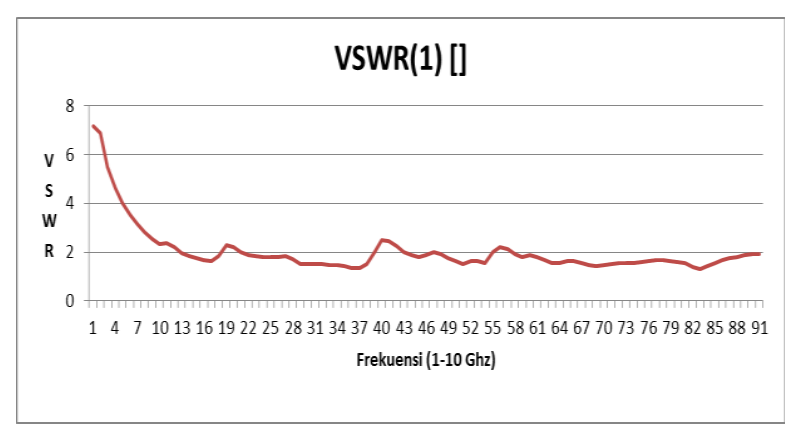

Gambar 9. Grafik nilai VSWR

Tabel $1 \mathrm{X}=\mathrm{VSWR}, \mathrm{Y}=$ Frekuensi

\begin{tabular}{|c|c|c|}
\hline Name & $X$ & $Y$ \\
\hline $\mathrm{m} 1$ & 23000 & 1.8404 \\
\hline $\mathrm{m} 2$ & 24000 & 1.7357 \\
\hline $\mathrm{m} 3$ & 25000 & 1.6602 \\
\hline $\mathrm{m} 4$ & 27000 & 1.8229 \\
\hline $\mathrm{m} 5$ & 30000 & 2.0051 \\
\hline
\end{tabular}

Nilai VSWR yang baik adalah sama dengan 1. Hal ini sangat sulit di dapat. Untuk praktek, nilai standar VSWR adalah kurang dari sama dengan 2 (VSWR $\leq 2$ ). Dari hasil analisis VSWR diatas bias dilihat bahwa antena tersebut termasuk antena UWB bias menerima lebih dari satu frekuensi. Dan pada frekuensi 2.4 mendapat VSWR 1.7357 artinya antena ini bias digunakan menangkap frekuensi WIFI yaitu 2,4 GHz.

2. Nilai Return Loss (LR)

Dari hasil analisa di dapat nilai sebagai berikut. 


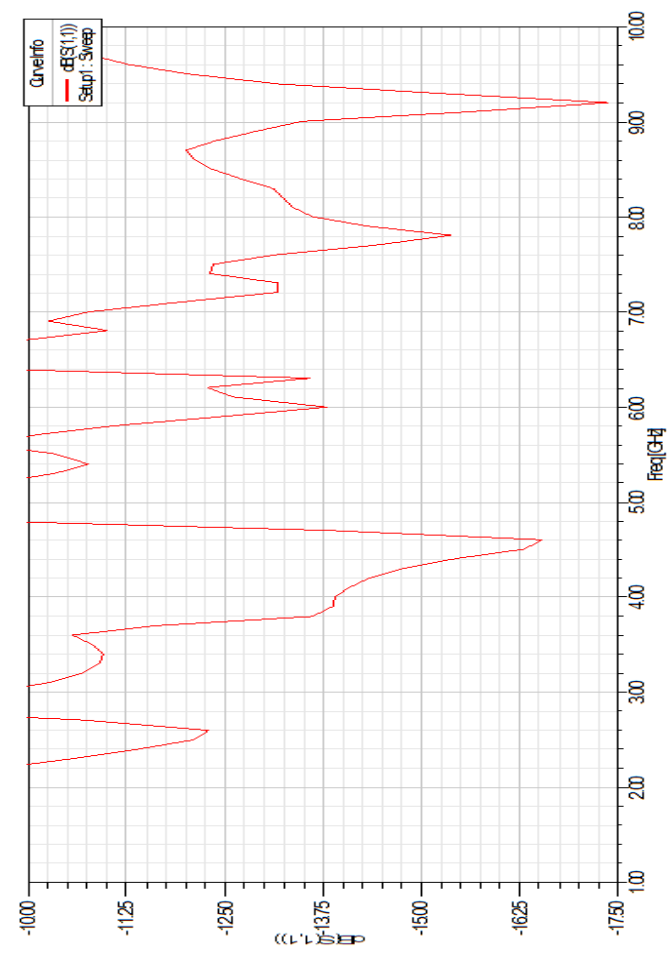

Gambar 10. Grafik Return Loss

Tabel 2 Frekuensi dan Return Loss

\begin{tabular}{|c|c|}
\hline $\begin{array}{c}\text { Frequensi } \\
{[\mathrm{GHz}]}\end{array}$ & $\mathrm{dB}(\mathrm{S})$ \\
\hline 2.3 & -10.5781 \\
\hline 2.4 & -11.4075 \\
\hline 2.5 & -12.1045 \\
\hline 2.6 & -12.2816 \\
\hline
\end{tabular}

3. Pola Radiation

Pola radiasi sirkular dengan $\pi=0^{\circ}$, dan $\alpha=$ $0^{\circ}$.

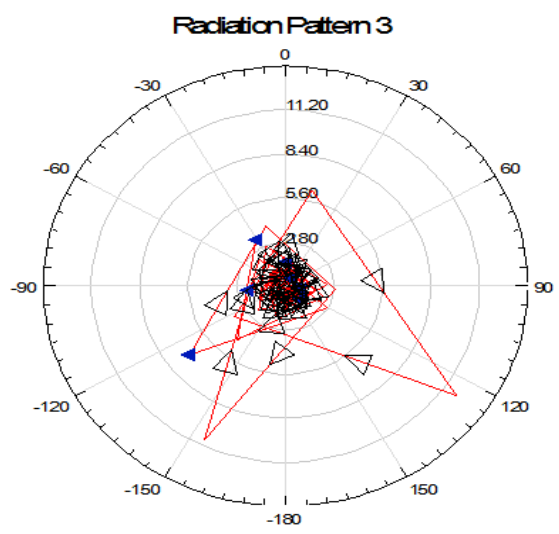

Gambar 11. Pola Radiasi Sirkular $=0^{\circ}$.

Pola radiasi dengan axial ratio $\pi=0^{\circ}$, dan $\alpha$

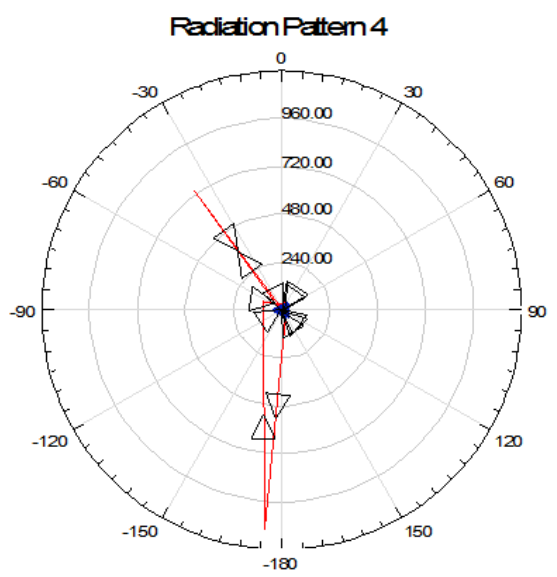

Gambar 12. Pola Radiasi Axial Ratio

4. Bandwith

Dari rumus perhitungan bandwith diatas tadi, maka di dapat nilai sebagai berikut.

$$
\begin{gathered}
B W=\frac{f_{h}-f_{l}}{f_{c}} X 100 \% \\
B W=\frac{f_{h}-f_{l}}{2}
\end{gathered}
$$

Untuk frekuensi wifi $\mathrm{f}_{\mathrm{l}}=2.3$ dan $\mathrm{f}_{\mathrm{h}}=2.7 \mathrm{f}_{\mathrm{c}}=$ 2.5 adalah 0.2

\section{Proses Fabrikasi Antena}

Setelah simulasi dan analisis dilakukan maka diperoleh hasil sesuai dengan yang kita harapkan, proses selanjutnya adalah proses fabrikasi atau pembuatan antena bentuk dimensi fisiknya sesuai dengan gambar desain yang sudah dibuat. Salah satu tujuan dari fabrikasi ini adalah untuk membandingkan pengukuran antena yang sudah difabrikasi dengan hasil dari simulasi.

Ada beberapa cara yang yang dapat dilakukan untuk pembuatan fabrikasi antena mikrostrip ini, salah satunya yang digunakan disini adalah dengan cara manual seperti pembuatan PCB untuk peralatan elektronik lainnya. Cara ini digunakan karena hanya untuk membuat fabrikasi dalam jumlah sedikit (1-5 buah fabrikasi), kalau untuk produksi massal kita tidak bisa menggunakan cara ini. Untuk keperluan pengujian kita bisa menggunakan cara manual ini.

Beberapa tahapan fabrikasi antena mikrostrip trisula dengan cara manual seperti yang 
dimaksudkan diatas tadi adalah sebagai berikut :

1.Persiapan bahan dan alat.

2. Menggambar desain antena sesuai dengan ukuran sebenarnya.

3. Menggambar pada bahan.

4. Melakukan etching.

5. Finishing.

Berikut tahapan yang sudah disebutkan seperti diatas, maka dapat dibuat bentuk flowchartnya untuk fabrikasi antena.

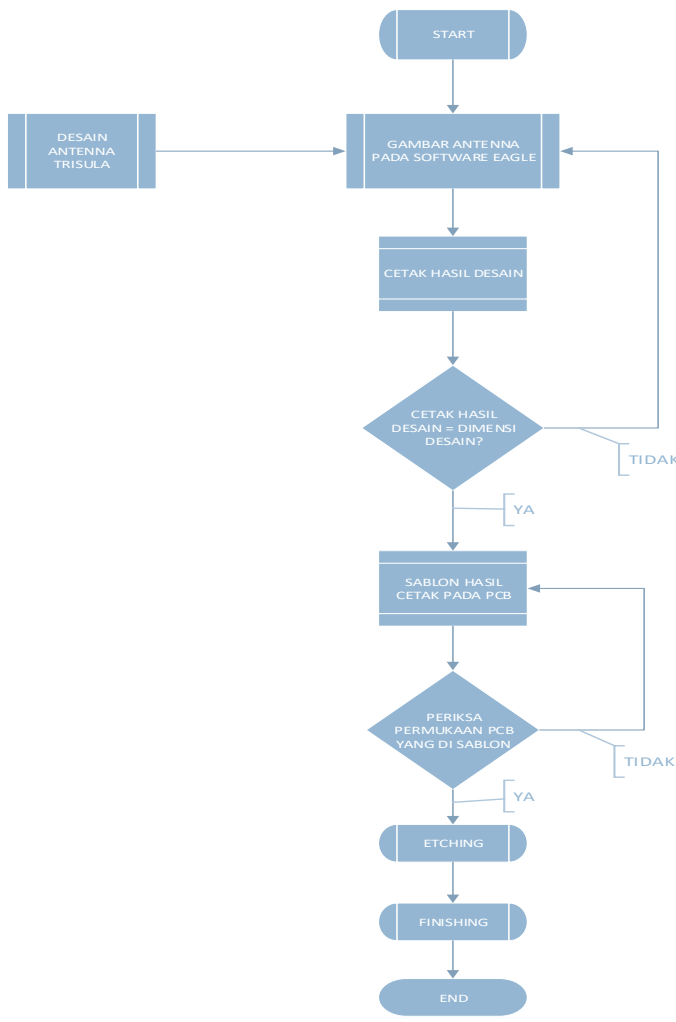

Gambar 13. Flowchart Fabrikasi Antena
Setelah melalui beberapa tahapan proses fabrikasi tadi, maka hasil dari fabrikasi antena dapat dilihat pada gambar berikut.

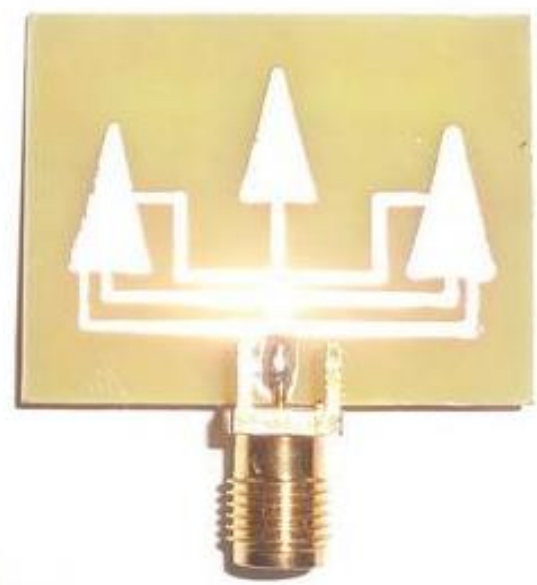

Gambar 14. Hasil Antena

\section{KESIMPULAN}

Dari hasil analisa dari ansoft menunjukan bahwa untena UWB diatas bias digunakan untuk menerima dari frekuensi wifi $2.4 \mathrm{GHz}$. Karena hasil dari analisis pada frekuensi $2.4 \mathrm{GHz}$ adalah sebagai berikut:

1. Frekuensi kerja $2-10 \mathrm{GHz}$

2. Pada frekuensi $2.4 \mathrm{GHz}$

a. VSWR nya adalah 1.7357 (< dari 2)

b. RL adalah -11.4075 (< dari -10 $\mathrm{dBi}$ )

Antena di atas bisa digunakan untuk menerima frekuensi wifi, yang pada perkembangannya dapat digunakan pada aplikasi RFID yang menggunakan perangkat telekomunikasi yang bekerja pada frekuensi 2,4 $\mathrm{GHz}$.

\section{REFERENSI}

[1] Balanis, Constantine, 2005. Antena Theory Analysis and Design Third Edition.Canada: John Wiley \& Sons, Inc

[2] R.Best ,Dr.Steven,1998.Antena Properties and Their Impact on Wireless System Perfomance.Manchester : Cushcraft Corporation 